\title{
Effect of caffeine on maximal oxygen uptake in wheelchair rugby players: A randomized, placebo-controlled, double-blind study
}

\author{
Iva Klimešováa ${ }^{1, *}$, Iva Machová1, Aleš Jakubec¹, and John Corkle ${ }^{2}$ \\ ${ }^{1}$ Faculty of Physical Culture, Palacký University Olomouc, Olomouc, Czech Republic; and ${ }^{2}$ College of Education, University \\ of Nebraska at Kearney, Kearney, NE, USA
}

Copyright: (C) 2017 I. Klimešová et al. This is an open access article licensed under the Creative Commons Attribution License (http://creativecommons.org/licenses/by/4.0/).

\begin{abstract}
Background: The positive effects of caffeine supplementation on strength-power and endurance performance in healthy athletes have been demonstrated in many studies. A possible mechanism for its ergogenic effect relates to its influence on the central nervous system. Post-traumatic complications in cervical spinal cord injury affect almost all body systems including the nervous system. For this reason, we expect that caffeine will have a different effect of performance in the group of athletes with spinal cord injuries. Objective: To examine the effects of caffeine supplementation on maximal aerobic power in elite wheelchair rugby players. Methods: Seven elite male wheelchair rugby players with complete cervical-level SCI (C4-Th1) were recruited (mean age: $28 \pm 5.42$ years; mean body mass index: $\left.26 \pm 2.84 \mathrm{~kg} / \mathrm{m}^{2}\right)$. The effect of caffeine was assessed by an incremental arm ergometer test until volitional exhaustion. The maximal oxygen uptake $\left(\mathrm{VO}_{2} \mathrm{max} / \mathrm{kg}\right)$, maximum power $(\mathrm{W} \max / \mathrm{kg})$, peak heart rate (HR peak), and intensity of perceived exertion (RPE) were measured. Participants performed the test twice with a two-week washout period. One hour before each exercise test subjects ingested a capsule of placebo or caffeine $(3 \mathrm{mg}$ per $\mathrm{kg}$ of body weight). The tests were applied in a double-blind, randomized, repeated-measures, and cross-over design. Wheelchair rugby players were chosen because of the expected high homogeneity of participants - in terms of the type and degree of disability, gender, and age of the players. Results: The monitored parameters were not significantly influenced by caffeine intervention as compared to placebo: $\mathrm{VO}_{2} \max / \mathrm{kg}(p=.40), \mathrm{W}$ max $/ \mathrm{kg}(p=.34)$, HR peak $(p=.50)$ and RPE $(p=.50)$. Conclusions: The current findings suggest that a caffeine dose of $3 \mathrm{mg} / \mathrm{kg}$ body mass does not improve oxygen uptake and maximal power in elite wheelchair rugby players.
\end{abstract}

Keywords: Paralympic, athletic performance, caffeine, wheelchair rugby

\section{Introduction}

Caffeine is a purine alkaloid that is found in various plants such as coffee or cocoa beans, tea leaves, kola nut or guarana. Caffeine is a common ingredient in soft drinks and over-the-counter drugs. European adults consume an average of $200 \mathrm{mg}(100-400 \mathrm{mg})$ of caffeine a day, mainly from coffee and tea (European Food Safety Authority, 2015). Caffeine represents one of the four most commonly consumed stimulants in sport, which are amphetamine, ephedrine, caffeine and cocaine. Amphetamine and cocaine are absolutely prohibited doping substances and ephedrine has a

\footnotetext{
* Address for correspondence: Iva Klimešová, Department of Natural Sciences in Kinanthropology, Faculty of Physical Culture, Palacký University Olomouc, třída Míru 117, 77111 Olomouc, Czech Republic. E-mail: iva.klimesova@upol.cz
}

specified limited concentration. In 2004 caffeine was removed from the list of prohibited substances, its use is allowed without limited concentrations now (World Anti-Doping Agency, 2016). The positive ergogenic effect of caffeine has been widely demonstrated in many studies for short-term and endurance performance in able-bodied athletes (Astorino \& Roberson, 2010; Close, Hamilton, Philip, Burke, \& Morton, 2016; Demura, Yamada, \& Terasawa, 2007; Foskett, Ali, \& Gant, 2009; McLellan, Caldwell, \& Lieberman, 2016; Woolf, Bidwell, \& Carlson, 2008). A potential mechanism for improving performance is a stimulating effect on the production of beta-endorphin. Increased production of this opioid hormone can impact the pain threshold, reduce the perception of fatigue and lead to an increase in strength and endurance (Goldstein et al., 2010). The popular theory says that caffeine reduces dependence on glycogen resources and increases the 
oxidation of intra and extra-muscular lipids during exercise. There is thus a better utilization of fat reserves as a source of energy for working muscles. According to Graham (2001), caffeine may work, in part, by creating a more favourable intracellular ionic environment in active muscle. This could facilitate force production by each motor unit. The evidence indicates that caffeine acts through its role as an adenosine receptor antagonist (Jenkins, 2005). Adenosine antagonism in adipocytes clearly leads to increased lipolysis and an increase in plasma free fatty acid concentration. Caffeine also slightly increases heart rate and myocardial contractility (McLellan et al., 2016). Goldstein et al. (2010) in its general review, which evaluated the results of 97 studies on the effect of caffeine during exercise, show that caffeine supplementation helps maintain maximum endurance performance, and is highly effective in intermittent performance. Also, according to this review, administration of caffeine is beneficial for competitive sports with high-intensity longer duration performance (including team sports such as football, hockey or rugby). At the same time, however, studies have repeatedly shown that enhanced athletic performance is individual and depends on many factors, e.g. habitual use of caffeine, the dose used and athletes' condition and level of fitness. It is also necessary to draw attention to the potential health risks of caffeine use. Using high doses can cause insomnia, digestive problems or headache (McLellan et al., 2016).

There is clear evidence that caffeine is an ergogenic aid for a variety of types of sports (Burke, 2009), although studies involving elite athletes with spinalcord injury are lacking. This disability generally affects the lower limbs of the body but depending on the severity of the disorder and the level of the lesion can also affect the upper limbs (Goosey-Tolfrey, Castle, Webborn, \& Abel, 2006). The sympathetic innervation of the heart derives from Th- 1 to Th- 4 and therefore spinal cord lesions at or above Th-4 may lead to inappropriate cardio-acceleration. As a consequence, maximal heart rate in persons with tetraplegia is often restricted (Figoni, 1993; Paulson, Bishop, Leicht, \& Goosey-Tolfrey, 2013; Tanhoffer, Tanhoffer, Raymond, Hills, \& Davis, 2012; Valent et al., 2007). Apart from the disturbed sympathetic innervation, individuals with tetraplegia have a low physical capacity as a consequence of the low active muscle mass and inactivity of the venous muscle pump (Valent et al., 2007).

The limited amount of knowledge on elite quadriplegic wheelchair athletes in comparison with healthy athletes is primarily due to population availability. However, the debut of wheelchair rugby at the 2000 Paralympics initiated a greater interest in this group of athletes. The present study focused on wheelchair rugby players because of the expected high homogeneity of participants - in terms of the type and degree of disability, gender, and age of the players.

Based on available literature, there are only three studies on the ergogenic effect of caffeine on the performance of wheelchair athletes in the available literature. In the first study, Graham-Paulson, Perret, Watson, and Goosey-Tolfrey (2016) investigated the effects of caffeine on sprint and 4 min maximal-push performance in wheelchair athletes. The study proved that acute caffeine supplementation, at the dosage $4 \mathrm{mg} / \mathrm{kg}$, can improve both $20 \mathrm{~m}$ sprint performance and a 1 off bout of short-term endurance performance in wheelchair athletes. On the other hand, the second study did not verify that the supplementation of caffeine, at the dosage $6 \mathrm{mg} / \mathrm{kg}$, provided an ergogenic effect on the $1,500 \mathrm{~m}$ exercise performance in wheelchair paraplegic elite athletes (Flueck, Mettler, \& Perret, 2014). Similarly, recent research from a team Flueck, Lienert, Schaufelberger, Krebs, and Perret (2015) proved an ergogenic effect of caffeine consumption $(6 \mathrm{mg} / \mathrm{kg}$ body weight) in a 3 min all-out arm crank test in paraplegic, but no in tetraplegic and able-bodied individuals. The study shoved a high inter-individual variability in performance between the subjects in group of tetraplegic subjects. Therefore the authors highlighted testing the supplement individually in every athlete.

Caffeine has been reported to alter muscle pain and perceptions of exertion that may alter willingness to continue exercise (Astorino, Cottrell, Talhami Lozano, Aburto-Pratt, \& Duhon, 2012). The aim of our study was to investigate whether caffeine supplementation at a dose of $3 \mathrm{mg}$ per kilogram $(\mathrm{mg} / \mathrm{kg})$ has effect on maximal oxygen uptake (VO2max $/ \mathrm{kg}$ ), maximum power (W max $/ \mathrm{kg}$ ), peak heart rate (HR peak), and rating of perceived exertion (RPE) in wheelchair rugby players. The incremental arm ergometer test until volitional exhaustion was used to be sensitive enough to detect changes in duration of the exercise and therefore it was hypothesized that caffeine would alter $\mathrm{W} \max / \mathrm{kg}$ and RPE exertion.

\section{Methods}

\section{Participants}

Seven male elite wheelchair rugby players with complete cervical-level SCI (C4-Th1), median age 27 years (range 21.0-34.0 years), body mass index $24.9 \mathrm{~kg} / \mathrm{m}^{2}$ (range $23.9-31.1 \mathrm{~kg} / \mathrm{m}^{2}$ ), 4.0 years of wheelchair rugby experience (range 1.5-11 years), volunteered in this study. The participants' anthropometric data are shown in Table 1. Table 2 presents disability and other evaluated initial parameters. All procedures were approved 
Table 1

Anthropometric characteristics

\begin{tabular}{lcccccccc}
\hline & $\begin{array}{c}\text { Age } \\
(\text { years })\end{array}$ & $\begin{array}{c}\text { Body weight } \\
(\mathrm{kg})\end{array}$ & $\begin{array}{c}\text { Body height } \\
(\mathrm{cm})\end{array}$ & $\begin{array}{c}\text { Body fat } \\
(\mathrm{kg})\end{array}$ & $\begin{array}{c}\text { Body fat } \\
(\%)\end{array}$ & $\begin{array}{c}\text { BMI } \\
\left(\mathrm{kg} / \mathrm{m}^{2}\right)\end{array}$ & $\begin{array}{c}\text { Fat free } \\
\text { mass }(\mathrm{kg})\end{array}$ & $\begin{array}{c}\text { WC } \\
(\mathrm{cm})\end{array}$ \\
\hline Subject 1 & 21 & 86.6 & 166.5 & 19.1 & 22.1 & 31.1 & 67.5 & 96.1 \\
Subject 2 & 22 & 85.9 & 186.5 & 16.8 & 19.6 & 24.6 & 69.1 & 93.2 \\
Subject 3 & 34 & 91.0 & 181.5 & 19.8 & 21.9 & 27.3 & 70.5 & 95.9 \\
Subject 4 & 26 & 88.0 & 188.0 & 11.8 & 13.4 & 24.9 & 76.2 & 91.0 \\
Subject 5 & 33 & 75.7 & 177.5 & 14.9 & 19.7 & 23.9 & 60.8 & 87.3 \\
Subject 6 & 27 & 85.0 & 170.0 & 15.7 & 18.5 & 29.4 & 69.3 & 90.5 \\
Subject 7 & 33 & 86.5 & 188.5 & 12.3 & 14.2 & 24.2 & 74.2 & 96.0 \\
$M$ & 28.0 & 85.5 & 179.8 & 15.8 & 18.5 & 26.5 & 69.7 & 92.9 \\
SD & 5.4 & 4.7 & 8.8 & 3.1 & 3.5 & 2.8 & 5.0 & 3.4 \\
Mdn & 27.0 & 86.5 & 181.5 & 15.7 & 19.6 & 24.9 & 69.3 & 93.0 \\
Minimum & 21.0 & 75.7 & 166.5 & 11.8 & 13.4 & 23.9 & 60.8 & 87.3 \\
Maximum & 34.0 & 91.0 & 188.5 & 19.8 & 22.1 & 31.1 & 76.2 & 96.1 \\
\hline
\end{tabular}

Note. $\mathrm{BMI}=$ body mass index $\mathrm{WC}=$ waist circumference.

Table 2

Disability and other evaluated characteristics

\begin{tabular}{lccccccc}
\hline Subject & $\begin{array}{c}\text { Level of spinal } \\
\text { cord injury }\end{array}$ & $\begin{array}{c}\text { IWRF classifi- } \\
\text { cation (points) }\end{array}$ & $\begin{array}{c}\text { Time post } \\
\text { injury (years) }\end{array}$ & $\begin{array}{c}\text { Training expe- } \\
\text { rience (years) }\end{array}$ & $\begin{array}{c}\text { Coffee } \\
\text { drinker }\end{array}$ & $\begin{array}{c}\text { Uses caffeine } \\
\text { as supplement }\end{array}$ & Smoker \\
\hline 1 & C6 & 2 & 4 & 1.5 & No & Yes & Yes \\
2 & C6-C7 & 2 & 3.5 & 3 & No & Yes & Yes \\
3 & C6-C7 & 2 & 16.5 & 4 & Yes & Yes & Yes \\
4 & C6-C7 & 1.5 & 4.5 & 3.5 & Yes & Yes & Yes \\
5 & C6-C7 & 2 & 10 & 7 & Yes & Yes & Yes \\
6 & Th1 & 2.5 & 15 & 5 & Yes & Yes & Yes \\
7 & C7 & 2.5 & 14 & 11 & Yes & Yes & Yes \\
\hline
\end{tabular}

Note. IWRF classification $=$ International Wheelchair Rugby Federation classification.

by the local ethical committee and written informed consent was obtained before the start of the study.

Notes for International Wheelchair Rugby Federation (IWRF) classification - there is a unique classification system in sport for persons with disabilities. Each sport must determine what impairment types are eligible for their respective sport (International Paralympic Committee, 2007). There are seven classes ranging from 0.5 to 3.5 with functional characteristics identified for each athlete class. In general, the 0.5 class includes those athletes with the most disability and the 3.5 class includes those athletes with the least disability or "minimal" disability eligible for the sport of wheelchair rugby. An athlete allocated a 4.0 sport class is not eligible to participate in wheelchair rugby (IWRF, 2015).

\section{Study design}

A double-blind, placebo-controlled, randomized, repeated-measures, and cross-over design was employed.
One hour before each performance test subjects ingested a capsule of placebo or caffeine. Participants underwent the performance test twice with a two-week washout period. The effect of caffeine was assessed by an incremental arm ergometer test until volitional exhaustion. The maximal oxygen uptake $\left(\mathrm{VO}_{2} \mathrm{max} /\right.$ $\mathrm{kg}$ ), maximum power ( $\mathrm{W} \max / \mathrm{kg}$ ), peak heart rate (HR peak), and intensity of perceived exertion (RPE) were measured.

\section{Performance test}

Participants completed ramp exercise to volitional fatigue on arm-crank ergometer (Ergoselect 400P, Ergoline, Bitz, Germany) to assess $\mathrm{VO}_{2}$ max. They warmed up for $6-3 \min 20 \mathrm{~W}$ and $3 \min 40 \mathrm{~W}$. The actual test started at a workload of $50 \mathrm{~W}$ for the first minute and then workload increased by $5 \mathrm{~W}$ every minute until, with encouragement, they reached volitional exhaustion. $\mathrm{VO}_{2} \max$ was considered the highest $\mathrm{VO}_{2}$ 
value in the final 30 seconds of the test. The cadence was maintained in the range 45 to 55 revolutions per minute. Participants' hands were fastened to the grips with elastic bandages. Expired air was analysed breath-by-breath using an automated gas analysis system (Ergostik, Geratherm Respiratory, Bad Kissingen, Germany). The gas analysers were calibrated immediately before each test using ambient air. Heart rate was continuously measured (Polar Vantage XL, Polar, Kempele, Finland). Environmental conditions across the 2 training venues were maintained by an airconditioning system between $20-22{ }^{\circ} \mathrm{C}$, and a relative humidity between $40-60 \%$.

Caffeine intake, sleep and training have been recorded by a questionnaire before every trial to guarantee equal testing conditions. Participants were prompted to standardize $48 \mathrm{~h}$ prior caffeine intake before every trial and to sleep at least seven hours the last two nights before the exercise testing.

\section{Rated perceived exertion}

The Borg 6 to 20 category scale (Borg, 1998) was used to obtain participants ratings of perceived exertion (RPE) scores after each test.

\section{Anthropometric measurements}

Body weight was measured using an electronic scale with an accuracy of $0.01 \mathrm{~kg}$ (Tanita WB-3000, Tanita, Tokyo, Japan). Participants were weighed on a chair and the weight of the chair was deducted from the total weight. Considering the type and degree of disability as well as the likelihood of lower limb contractures or increased spasticity in individuals with cervical spine injury (EriksHoogland et al., 2011), body height was measured in a supine position (to the nearest $1 \mathrm{~mm}$ ). The body mass index was calculated by dividing weight in kilograms by height in metres. Waist circumference was measured after normal expiration in the lying position according to the recommended technique - at the midpoint between the superior iliac crest and the lowest rib (World Health Organization, 2008). For measurement, the anthropometric non-stretch tape was placed directly on the skin with the participants' arms by their sides. Body composition was measured using bioelectrical impedance analysis (Quadscan 4000, Bodystat, Douglas, Isle of Man, British Isles) which allowed the measurement of individuals who could not assume an upright position. Prior to measurement subjects were placed in the supine position for a minimum of 4 minutes. All measurements were conducted by the same investigator.

\section{Caffeine dosage}

The participants randomly received gelatine capsules with caffeine or placebo 60 minutes before the exercise test. Identical caffeine and placebo capsules were prepared. The caffeine capsules were packaged in $30 \mathrm{mg}$ and $15 \mathrm{mg}$ of anhydrous caffeine (Nutrend D.S., Olomouc, Czech Republic), the placebo capsules contained inert microcrystallines. A researcher from a separate institution, who had no interaction with the subjects, coded the caffeine and placebo capsules and assigned the proper dosing for each individual. Dosage was weight-dependent $3 \mathrm{mg}$ per kilogram, for example, the participant weighed $75.7 \mathrm{~kg}$ received 8 capsules of caffeine ( 7 capsules contained $30 \mathrm{mg}$ of caffeine and 1 capsule contained $15 \mathrm{mg}$ of caffeine) and 8 capsules of placebo, respectively. This dosage is equal to approximately one and a half cups of brewed coffee.

This dose was chosen because it is within the supplementation range $(3.0-6.0 \mathrm{mg} / \mathrm{kg}$ prior to exercise) shown to improve sport performance in trained athletes (Burke, 2009; Goldstein et al., 2010; Klimešová, 2015; Máček \& Radvanský, 2011). The capsules were swallowed with $500 \mathrm{ml}$ of tap water.

\section{Statistical analysis}

For the statistical analysis, Statistica (Version 12.0; StatSoft, Tulsa, OK, USA) was used. Due to the character of data measured (low number of subjects) we applied a non-parametric procedures. To assess the effect of caffeine or placebo on each individual Wilcoxon pair test was employed. The values were considered to be significantly different if $p<.05$.

\section{Results}

Table 1 and Table 2 present the disability and anthropometric characteristics of the athletes. The group was relatively homogenous in athlete impairment, but heterogeneous with respect to body weight, body fat, and body fat free mass. The most frequent level of spinal cord injury was of C-6 or C-7. These disabilities generally affect the lower limbs of the body but depending on the severity of the disorder and the level of the lesion also affect the upper limbs (Goosey-Tolfrey et al., 2006). Spinal nerve root C-6 controls the wrist extensors, muscles like the extensor carpi radialis longus, extensor carpi radialis brevis, and extensor carpi ulnaris that control wrist extension and hyperextension and also provides some innervation to the biceps. C-6 patients have musculature that permits most shoulder motion, elbow bending, but not straightening, and active wrist extension which permits tenodesis, opposition of thumb to index finger, and finger flexion. Spinal nerve root C-7 innervates three main arm muscles, the triceps, the wrist flexors and the metacarpophalangeal extensors. As a result, enhanced grasp strength and a 
weak triceps muscle will reduce the throwing ability of one who has the C-7 nerve involved (Rhoades \& Tanner, 1995). We have to reckon with the fact that there is large variability in the amount of upper limb musculature remaining under voluntary control in tetraplegia.

The participants' wheelchair-rugby classification ranged from 1.5 to 2.5. All participants were smokers (caffeine clearance is stimulated by smoking; Murphy et al., 1988) and had repeated experience with the use of caffeine. Athletes reported moderate caffeine consumption in the range of one to three cups of coffee per day or used caffeine supplements. An average cup of coffee contains approximately $150 \mathrm{mg}$ of caffeine (Klimešová, 2015); it means that daily caffeine intake from coffee was $1.6-5.9 \mathrm{mkg} / \mathrm{kg}$ in our research group.

In the present study, the achieved values of $\mathrm{VO}_{2} \max / \mathrm{kg}$, W $\max / \mathrm{kg}$, HR peak, and RPE were highly variable between subjects. The range of $\mathrm{VO}_{2} \max$ reached during the test was $7.10-15.70 \mathrm{ml} / \mathrm{kg} / \mathrm{min}$ for placebo and $8.6-16.1 \mathrm{ml} / \mathrm{kg} / \mathrm{min}$ for caffeine, the range of the $\mathrm{W} \max$ was $0.75-1.10 \mathrm{~W} / \mathrm{kg}$ for placebo and $0.65-1.11 \mathrm{~W} / \mathrm{kg}$ for caffeine, the range of the HR peak was $84-121$ beats/min for placebo and 83-143 beats/min for caffeine, and the range of RPE was 15-18 points for placebo and 15-18 points for caffeine.

The results presented in the Table 3 showed that caffeine supplementation had no significant effect on $\mathrm{VO}_{2} \max / \mathrm{kg}, \mathrm{W} \max / \mathrm{kg}$, HR peak, and RPE. In addition, there are no differences between the mean of respiratory exchange ratio $(p=.67)$ and the test duration $(p=.67)$ for placebo and caffeine, respectively. The median respiratory exchange ratio was 1.13 (range 1.03-1.19) and 1.14 (range 1.03-1.21) for placebo and caffeine, respectively; the median of the test duration was $4.37 \mathrm{~min}$ (range $0.38-10.00 \mathrm{~min}$ ) and $5.80 \mathrm{~min}$ (range 0.36-10.00) for placebo and caffeine, respectively.

\section{Discussion}

There is limited research that has examined the relationship between the use of supplements and sport performance in elite athletes with quadriplegia. The general concept that high values of aerobic and anaerobic power strongly correlate with endurance and speed performance is not valid for this population. Next, due to their disability these athletes have problems reaching higher HR max (Figoni, 1993; Paulson et al., 2013; Tanhoffer et al., 2012; Valent et al., 2007), control their thermoregulation (Krassioukov et al., 2007), maintain adequate arterial blood pressure (Krassioukov et al., 2007), low stroke volume during training or competition session (Figoni, 1993). The data obtained from the present study provide a unique opportunity to expand knowledge about the exercise physiology of highly trained wheelchair rugby players.

Use of nutritional supplements is common among athletes with impairment (Graham-Paulson et al., 2016), but the available evidence of its efficacy in this population is lacking. To our knowledge, no previously published studies have directly sought to examine the effect of caffeine supplementation on maximal aerobic power in elite wheelchair athletes.

Response to physical activity fails to meet the needs of the body and typically results in low blood pressure, resulting in reduced endurance and a decrease in sports performance (Zwierzchowska, Sadowska-Krępa, Głowacz, Mostowik, \& Maszczyk, 2015). The values of monitored parameters of elite wheelchair rugby players, in the present study, were in the range of values reported by Van Loan, McCluer, Loftin, and Boileau (1987). The authors Van Loan et al. (1987) worked with a group of 13 quadriplegics aged $29.6 \pm 2.5$ years, with the height of the lesion $\mathrm{C} 5-\mathrm{C} 8$. Involved athletes were not wheelchair rugby players but participated in activities such as basketball, archery and athletics. These athletes reached $\mathrm{VO}_{2} \mathrm{max} / \mathrm{kg} 12.0 \pm 3.3 \mathrm{ml} / \mathrm{kg} / \mathrm{min}$ during maximal arm cranking tests. In our research sample, the

Table 3

Effect of caffeine or placebo supplementation

\begin{tabular}{|c|c|c|c|c|c|c|c|c|}
\hline & \multirow[b]{2}{*}{$N$} & \multicolumn{3}{|c|}{ Placebo } & \multicolumn{3}{|c|}{ Caffeine } & \multirow{2}{*}{$\begin{array}{l}\text { Wilcoxon } \\
\text { test } p \text { value }\end{array}$} \\
\hline & & $M \pm S D$ & $M d n$ & Range & $M \pm S D$ & $M d n$ & Range & \\
\hline $\begin{array}{l}\text { Maximum oxygen } \\
\text { uptake }(\mathrm{ml} / \mathrm{kg} / \mathrm{min})\end{array}$ & 7 & $11.35 \pm 2.6$ & 11.60 & $7.10-15.70$ & $12.02 \pm 2.33$ & 11.60 & $8.60-16.10$ & .40 \\
\hline $\begin{array}{l}\text { Maximum power } \\
(\mathrm{W} / \mathrm{kg})\end{array}$ & 7 & $0.83 \pm 0.15$ & 0.81 & $0.64-1.10$ & $0.83 \pm 0.14$ & 0.81 & $0.65-1.11$ & .35 \\
\hline $\begin{array}{l}\text { Peak heart rate } \\
\text { (beats/min) }\end{array}$ & 7 & $106.00 \pm 13.09$ & 102 & $84-121$ & $110.86 \pm 21.97$ & 103 & $83-143$ & .50 \\
\hline $\begin{array}{l}\text { Rating of perceived } \\
\text { exertion (points) }\end{array}$ & 7 & $15.57 \pm 1.13$ & 15 & $15-18$ & $16.00 \pm 1.15$ & 16 & $15-18$ & .50 \\
\hline
\end{tabular}


average values of achieved maximal oxygen uptake were $11.35 \pm 2.6 \mathrm{ml} / \mathrm{kg} / \mathrm{min}$ and $12.02 \pm 2.33 \mathrm{ml} / \mathrm{kg} / \mathrm{min}$ in the placebo and caffeine.

As with maximal oxygen uptake, our results of HR peak were comparable with Van Loan et al. (1987). For our athletes, the mean HR peak were $106 \pm 13$ beats/min for placebo and $111 \pm 22$ beats/min for caffeine. Van Loan et al. (1987) showed $109 \pm 17$ beats/min in their tetraplegic group. When analysing the HR data it was clear that a large inter-individual variability was present during the tests (HR peak 83-143 beats/min). Research shows that the individuals with complete spinal injuries at or above Th-4 generally exhibit dramatically diminished cardiac acceleration with maximal heart rates less than 130 beats/min (Jacobs \& Nash, 2004). The low peak HRs are the result of the well documented evidence suggesting a lack of sympathetic innervation to the heart for lesions at the cervical level (Campbell, Williams, \& Lakomy, 2002; Goosey-Tolfrey et al., 2006). As a consequence of the disturbed sympathetic innervation, autonomic dysreflexia may occur in subjects with a lesion level at or above Th-6. Autonomic dysreflexia may result in an uncontrolled elevation of blood pressure, and during exercise, this may lead to sudden changes in HR and eventually a higher HRpeak and $\mathrm{VO}_{2}$ peak (Bhambhani, 2002; Krassioukov et al., 2007; Mazzeo, Santamaria, \& Iavarone, 2015).

Elite athletes with disability and their coaches are looking for ways how to work and improve their performance. Similar to able bodied athletes there are some ways which are dangerous for them but can improve their performance by boosting it. Experimental evidence indicates that boosting can improve performance time by $10 \%$ in elite wheelchair marathon racers during simulated racing, as a result of increased oxygen utilisation in the boosted state (Bhambhani, 2002). According the health risks these ways are prohibited by International Paralympic Committee. The use of supplements which can have an effect on the mentioned physiological restrictions and without health risks can be a way for athletes with quadriplegia to reach higher performance.

The main finding of this study was that caffeine supplementation had no effect on the maximal oxygen uptake $\left(\mathrm{VO}_{2} \max / \mathrm{kg}\right.$ ), maximum power ( $\mathrm{W} \max / \mathrm{kg}$ ), peak heart rate (HR peak), and intensity of ratings perceived exertion (RPE) in elite wheelchair rugby players compared with the placebo treatment (Table 3).

The evidence supporting the ergogenic effects of caffeine is limited. In general, only one study explored the positive influence of caffeine on exercise performance in athletes with tetraplegia (Graham-Paulson et al., 2016). These researchers have focused on caffeine supplementation in $20 \mathrm{~m}$ sprint performance and a 1 off bout of short-term endurance performance in wheelchair athletes. However, the study showed caffeine has improved cycling but not handcycling. Flueck et al. (2014) demonstrated no ergogenic effect of caffeine on 1,500 m exercise performance in elite wheelchair athletes. The time to complete $1,500 \mathrm{~m}$ was not significantly different between the four treatments (placebo, caffeine, sodium citrate, combination). Moreover, maximal lactate concentrations were significantly higher in the caffeine and the combination treatment compared with placebo. In addition, Flueck et al. (2015) proved positive effect of caffeine consumption in a 3 min all-out arm crank test only in paraplegic participants. However, study showed no enhancement in short-duration exercise performance in tetraplegic and able-bodied individuals.

Based on the research presented (Burke, 2009; Demura et al., 2007; Foskett et al., 2009; Goldstein et al., 2010; Woolf et al., 2008) it is apparent that moderate caffeine supplementation in the range of $3-6 \mathrm{mg} / \mathrm{kg}$ can be advantageous for either endurance or sprint performance, but only in able-bodied athletes.

The psychostimulant effect of caffeine is reported frequently in able-bodied athletes (Smith, Sutherland, $\&$ Christopher, 2005) and may have contributed to the improved RPE. A met analysis of 21 studies that had measured the effect of caffeine on RPE demonstrated that caffeine reduces RPE by $5.6 \%$ in comparison with placebo, but again only in able-bodied athletes (Doherty \& Smith, 2005). Graham-Paulson et al. (2016) demonstrated no influence of caffeine supplementation on changes in RPE in wheelchair athletes.

Failure to prove the effects of caffeine can be explained by several reasons. Firstly, a reduction of active muscle mass, differences in the muscle fibre distribution and function in the upper extremities between able-bodied and athletes with spinal injury may explain the lack of ergogenic effect of caffeine (Jacobs \& Nash, 2004). Secondly, arm exercise does not engage sufficient muscle mass to elicit the effects of caffeine. Moreover, muscle fibre type distribution might also play an important role, as arm muscles considerably differ from leg muscles in this respect. The evidence from biopsies suggest that the triceps muscle exhibits a greater proportion of type II muscle fibres than the legs (Mygind, 1995), and type II fibres have been shown to be less sensitive to caffeine compared to type I fibres (Mitsumoto et al., 1990). That said, performance gains may be less likely following caffeine supplementation during exercise which relies on the arms (with a lower proportion of type I fibres). The current study of Graham-Paulson et al. (2016) adds further evidence that caffeine may have different effects on arm and leg muscles. The study proved that caffeine 
(a dose of $4 \mathrm{mg} / \mathrm{kg}$ ) improved cycling but not handcycling time trial performance in able-bodied males. Graham-Paulson et al. (2016) give an explanation that the lack of improvement during handcycling may be due to smaller active muscle mass, blood lactate concentration and/or participants' training status. Furthermore, the reason may also be testing a small dose of caffeine, which for players accustom to consuming it on a regular basis may be insufficient. All subjects involved in this study reported daily caffeine intake in the form of coffee consumption or caffeine supplementation. For caffeine supplementation we suggested a dosage of $3 \mathrm{mg} / \mathrm{kg}$ body mass which should be appropriate for optimal performance as higher dosage showed no further ergogenic effect in able-bodied subjects (Goldstein et al., 2010). But, it is possible that higher doses would lead to different results in this specific group. Flueck et al. (2015) proved that caffeine supplementation, at the dosage $6 \mathrm{mg} / \mathrm{kg}$, can improve $3 \mathrm{~min}$ all-out arm crank exercise performance in paraplegic participants. However, no ergogenic effect was detected in tetraplegic and able-bodied groups. Finally, a reduced sympathetic stimulation (neuronal and circulating catecholamines) as well as other possible factors (neurogenic, humoral, etc.) in athletes with spinal injury could cause that the used dose of caffeine was insufficient to stimulate sympathetic nervous system. Autonomic nervous system impairment limits control of blood flow and cardiac output, and maximal heart rate. Moreover, the autonomic disruption of the gastrointestinal system may decline digestion, resorption, absorption and excretion of nutrients, including caffeine. Unfortunately, the rate of caffeine absorption and metabolism were not measured in the current study.

Consequently, it may not be possible to directly transfer the findings from studies involving able-bodied athletes to athletes with a physical impairment. Further research is needed for a better understanding of these complex mechanisms.

\section{Limitation of the study}

The main limitations of this study were its cross-sectional design, a relatively small number of participants and the lack of available literature on the subject to contrast the obtained data. On the other hand, participants were fairly homogenous in physical impairments; hence the findings can be generalized to the sport and to a specific impairment.

Another limitation was lack of measurement of epinephrine, norepinephrine and plasma caffeine levels.

\section{Conclusion}

The current findings suggest that the supplementation with caffeine dose of $3 \mathrm{mg} / \mathrm{kg}$ body mass does not have any ergogenic effect on maximal performance in elite wheelchair rugby players and the supplement did not improve participants' intensity of perceived exertion.

\section{Acknowledgments}

The authors want to thank the individuals who participated as subjects in this study. Also, the authors would like to thank the company Nutrend D. S., a. s. for providing the capsules with caffeine and placebo. The company had no role in the study design, data collection and analysis or preparation of the manuscript.

\section{Conflict of interest}

There were no conflicts of interest.

\section{References}

Astorino, T. A., Cottrell, T., Talhami Lozano, A., Aburto-Pratt, K., \& Duhon, J. (2012). Effect of caffeine on RPE and perceptions of pain, arousal, and pleasure/displeasure during a cycling time trial in endurance trained and active men. Physiology and Behavior, 106, 211-217.

Astorino, T. A., \& Roberson, D. W. (2010). Efficacy of acute caffeine ingestion for short-term high-intensity exercise performance: A systematic review. Journal of Strength and Conditioning Research, 24, 257-265.

Bhambhani, Y. (2002). Physiology of wheelchair racing in athletes with spinal cord injury. Sports Medicine, 32, 23-51.

Borg, G. (1998). Borg's perceived exertion and pain scales. Champaign, IL: Human Kinetics.

Burke, L. M. (2009). Caffeine and sports performance. Indian Journal of Natural Products and Resources, 8, 216.

Campbell, I. G., Williams, C., \& Lakomy, H. K. (2002). Physiological and metabolic responses of wheelchair athletes in different racing classes to prolonged exercise. Journal of Sports Sciences, 22, 449-456.

Close, G., Hamilton, D. L., Philp, A., Burke, L. M., \& Morton, J. (2016). New strategies in sport nutrition to increase exercise performance. Free Radical Biology and Medicine, 98, 144-158.

Demura, S., Yamada, T., \& Terasawa, N. (2007). Effect of coffee ingestion on physiological responses and ratings of perceived exertion during submaximal endurance exercise. Perceptual and Motor Skills, 105, 1109-1116.

Doherty, M., \& Smith, P. M. (2005). Effects of caffeine ingestion on rating of perceived exertion during and after exercise: A meta-analysis. Scandinavian Journal of Medicine and Science in Sports, 15, 69-78.

Eriks-Hoogland, I., Hilfiker, R., Baumberger, M., Balk, S., Stucki, G., \& Perret, C. (2011). Clinical assessment of 
obesity in persons with spinal cord injury: Validity of waist circumference, body mass index, and anthropometric index. Journal of Spinal Cord Medicine, 34, 416-422.

European Food Safety Authority. (2015). Scientific opinion on the safety of caffeine. EFSA Journal, 13(5), 1-21.

Figoni, S. F. (1993). Exercise responses and quadriplegia. Medicine \& Science in Sports \& Exercise, 5, 433-441.

Flueck, J. L., Lienert, M., Schaufelberger, F., Krebs, J., \& Perret, C. (2015). Ergogenic effects of caffeine consumption in a 3 min all-out arm crank test in paraplegic and tetraplegic compared with able-bodied individuals. International Journal of Sport Nutrition and Exercise Metabolism, 26, 584-593.

Flueck, J. L., Mettler, S., \& Perret, C. (2014). Influence of caffeine and sodium citrate ingestion on $1,500 \mathrm{~m}$ exercise performance in elite wheelchair athletes: A pilot study. International Journal of Sport Nutrition and Exercise Metabolism, 24, 296-304.

Foskett, A., Ali, A., \& Gant, N. (2009). Caffeine enhances cognitive function and skill performance during simulated soccer activity. International Journal of Sport Nutrition, 19, 410-423.

Goldstein, E. R., Ziegenfuss, T., Kalman, D., Kreider, R., Campbell, B., Wilborn, C., ... Antonio, J. (2010). International society of sports nutrition position stand: Caffeine and performance. Journal of the International Society of Sports Nutrition, 7, 5.

Goosey-Tolfrey, V., Castle, P., Webborn, N., \& Abel, T. (2006). Aerobic capacity and peak power output of elite quadriplegic games players. British Journal of Sports Medicine, 40, 684-687.

Graham, T. E. (2001). Caffeine and exercise. Sports Medicine, $31,785-807$

Graham-Paulson, T. S., Perret, C., Watson, P., \& Goosey-Tolfrey, V. L. (2016). Improvement of sprint performance in wheelchair sportsmen with caffeine supplementation. International Journal of Sports Physiology and Performance, 11, 214-220.

International Paralympic Committee. (2007). International Paralympic Committee classification code and international standards. Retrieved from http://www.paralympic.org/sites/ default/files/document/120201084329386_2008_2_Classification_Code6.pdf

International Wheelchair Rugby Federation. (2015). International Wheelchair Rugby Federation classification manual (3rd ed.). Retrieved from http://www.iwrf.com/resources/ iwrf_docs/IWRF_Classification_Manual_3rd_Edition_rev2015_(English).pdf

Jacobs, P., \& Nash, M. (2004). Exercise recommendations for individuals with spinal cord injury. Sports Medicine, 34, 727-751.

Jenkins, S. P. R. (2005). Sports science handbook: The essential guide to kinesiology, sport and exercise science. Brentwood, United Kingdom: Multi-Science.

Klimešová, I. (2015). Základy sportovní výživy [Sports nutrition basics]. Olomouc, Czech Republic: Palacký University Olomouc.

Krassioukov, A. V., Karlsson, A. K., Wecht, J. M., Wuermser, L. A., Mathias, C. J., \& Marino, R. J. (2007). Assessment of autonomic dysfunction following spinal cord injury: Rationale for additions to international standards for neurological assessment. Annals of Rehabilitation Medicine, 44, 103-112.
Máček, M., \& Radvanský, J. (2011). Fyziologie a klinické aspekty pohybové aktivity [Physiology and clinical aspects of physical activity]. Prague, Czech Republic: Galén.

Mazzeo, F., Santamaria, S., \& Iavarone, A. (2015). "Boosting" in Paralympic athletes with spinal cord injury: Doping without drugs. Functional Neurology, 30, 91-98.

McLellan, T. M., Caldwell, J. A., \& Lieberman, H. R. (2016). A review of caffeine's effects on cognitive, physical and occupational performance. Neuroscience \& Biobehavioral Reviews, 71, 294-312.

Mitsumoto, H., DeBoer, G. E., Bunge, G., Andrish, J. T., Tetzlaff, J. E., \& Cruse, P. (1990). Fiber-type specific caffeine sensitivities in normal human skinned muscle fibers. Anesthesiology, 72, 50-54.

Murphy, T. L., McIvor, C., Yap, A., Cooksley, W. G. E., Halliday, J. W., \& Powell, L. W. (1988). The effect of smoking on caffeine elimination: Implications for its use as a semiquantitative test of liver function. Clinical and Experimental Pharmacology and Physiology, 15, 9-13.

Mygind, E. (1995). Fibre characteristics and enzyme levels of arm and leg muscles in elite cross-country skiers. Scandinavian Journal of Medicine and Science in Sports, 5, 76-80.

Paulson, T. A. W., Bishop, N. C., Leicht, C. A., \& Goosey-Tolfrey, V. L. (2013). Perceived exertion as a tool to self-regulate exercise in individuals with tetraplegia. European Journal of Applied Physiology, 113, 201-209.

Rhoades, R., \& Tanner, G. A. (Eds.). (1995). Medical physiology. Boston, MA: Little, Brown.

Smith, A., Sutherland, D., \& Christopher, G. (2005). Effects of repeated doses of caffeine on mood and performance of alert and fatigued volunteers. Journal of Psychopharmacology, 19, 620-626.

Tanhoffer, R. A., Tanhoffer, A. I. P., Raymond, J., Hills, A. P., \& Davis, G. M. (2012). Comparison of methods to assess energy expenditure and physical activity in people with spinal cord injury. Journal of Spinal Cord Medicine, 35, 35-45.

Valent, L. J. M., Dallmeijer, A. J., Houdijk, H., Slootman, J., Janssen, T. W. J., Hollander, A. P., \& van der Woude, L. H. V. (2007). The individual relationship between heart rate and oxygen uptake in people with a tetraplegia during exercise. Spinal Cord, 45, 104-111.

Van Loan, M. D., McCluer, S., Loftin, J. M., \& Boileau, R. A. (1987). Comparison of physiological responses to maximal arm exercise among able-bodied, paraplegics and quadriplegics. Paraplegia, 25, 397-405.

Woolf, K., Bidwell, W. K., \& Carlson, A. G. (2008). The effect of caffeine as an ergogenic aid in anaerobic exercise. International Journal of Sport Nutrition and Exercise Metabolism, 18, 412-429.

World Anti-Doping Agency. (2016). The 2016 prohibited list - International Standards. Retrieved from https://www.wadaama.org/sites/default/files/resources/files/wada-2016-prohibited-list-en.pdf

World Health Organization. (2008). Waist circumference and waist-hip ratio report of a WHO expert consultation. Geneva, Switzerland: Author.

Zwierzchowska, A., Sadowska-Krępa, E., Głowacz, M., Mostowik, A., \& Maszczyk, A. (2015). Comparison of designated coefficients and their predictors in functional evaluation of wheelchair rugby athletes. Journal of Human Kinetics, 48, 149-156. 